Session 1330

\title{
Enhancing Conceptual Understanding With Concept Maps and Concept Questions
}

\author{
David L. Darmofal, Diane H. Soderholm, Doris R. Brodeur \\ Massachusetts Institute of Technology
}

\begin{abstract}
Conceptual understanding is the ability to apply knowledge across a variety of instances or circumstances. It differs from declarative knowledge learning in that declarative knowledge involves a memorization of an association between two or more entities. Conceptual understanding involves the ability to apply knowledge across a variety of previously unencountered instances. ${ }^{1}$ Conceptual understanding is considered lasting if the concept represents a "big idea" having lasting value beyond the classroom, resides at the heart of the discipline, requires uncoverage of misconceptions, and offers the potential to engage students. ${ }^{2}$
\end{abstract}

Several strategies can be used to teach and assess concepts, e.g., inquiry, exposition, analogies, mnemonics, imagery, concept maps, and concept questions. This paper focuses on the last two -- concept maps and concept questions. Concept maps are twodimensional, hierarchical diagrams that show the structure of knowledge within a discipline. They are composed of concept labels, each enclosed in a box or oval, a series of labeled linking lines and general-to-specific organization. ${ }^{3-4}$ Concept questions focus on a single concept, are not solvable by relying solely on equations, reveal common difficulties with the concepts, and have several plausible answers based on typical student misunderstandings. ${ }^{5-6}$ This paper describes current progress at MIT in the development and use of concept maps and concept questions in aerospace engineering.

\section{Introduction}

The Department of Aeronautics and Astronautics at the Massachusetts Institute of Technology (MIT) is engaged in a number of educational initiatives to reform its educational programs. To achieve its program goals, the department has designed a curriculum that parallels the context of the life cycle of an engineering system, i.e., the Conception, Design, Implementation, and Operation (CDIO) of engineering systems shapes the content, scope, and sequence of the undergraduate curriculum. At the same time, the department is investigating the findings of educational research to improve faculty's ability to guide student learning, with the goal of applying best practices in teaching and learning to engineering education. 
During the past four years, MIT Aero/Astro faculty have introduced pedagogical techniques into a variety of aerospace engineering courses seeking to improve conceptual understanding. In particular, "muddiest-point-in-the-lecture" cards ${ }^{7-8}$ and in-class concept questions ${ }^{9}$ coupled with automated personal response systems ${ }^{10}$ are being used in the sophomore core courses and in the junior-level courses in thermal energy and aerodynamics. Unlike traditional lectures, these active learning strategies engage students with the conceptual material during class. When implemented properly, active learning improves conceptual understanding, decreases feedback time between faculty and students, encourages self-driven learning, and clarifies common misconceptions. ${ }^{11-18}$

\section{Concept Learning and Constructivism}

Concepts can be classified as concrete concepts and defined, or abstract, concepts. Concrete concepts are ideas of common objects, e.g., wing, jet engine, or object qualities like elliptical, red, smooth. Concrete concepts are learned by the presentation of a variety of instances and noninstances whose characteristics can be directly perceived by the learner. ${ }^{19}$ For most engineering students, understanding concrete concepts is usually not difficult. On the other hand, understanding defined concepts can be a challenge. Defined, or abstract, concepts are rules that classify objects or events. These concepts require verbal definitions if they are to be learned in an adequate way, e.g., drag, turbulence, boundary layer. A student who has understood a defined concept has learned the classifying rule and is able to apply it to any instance of the class. It is not essential that the learner know the definition itself in order to show that he/she has learned the concept. Students show their understanding of abstract concepts by using their knowledge, adapting it, and customizing it. ${ }^{20}$ Students who begin to organize their knowledge around the major concepts of a discipline, have begun the transformation from novice to expert thinker. ${ }^{21}$ Assessment of conceptual understanding requires the application of knowledge to new problems and diverse situations.

Constructivism presents a view of learning that is particularly useful in describing conceptual learning. The constructivist view is that individuals must actively construct their knowledge through testing concepts on prior experience, applying these concepts to new situations, and integrating the concepts into prior knowledge. ${ }^{22-23}$ If new knowledge conflicts with past experiences, these new concepts will be difficult to assimilate and learning is generally superficial and short-term. For purposes of teaching, a constructivist instructor must understand students' pre-existing knowledge and encourage students to confront knowledge that conflicts with the concepts being taught.

Traditional teaching uses a transmittal approach in which students are assumed to gain knowledge while passively listening to lectures. This style of teaching is in direct conflict with a constructivist view of learning as it does not actively engage students, nor does it force students to confront their misconceptions. In pursuing a pedagogical approach to enhance conceptual understanding, students must 1) become dissatisfied with their preexisting knowledge; 2) possess some minimum understanding of the scientific concept; 3 ) believe the concept is plausible; and 4) believe the concept is useful in explaining known 
behavior. ${ }^{24}$ The transition to conceptual-change instruction from the long-standing transmittal approach is difficult.

\section{Concept Maps and Concept Questions in Engineering Education}

In the past ten years, concept maps and concept questions have been used to teach and assess conceptual understanding in mathematics and science education. ${ }^{25-29}$ Now, these tools are being applied to humanities and social sciences, and to some extent to engineering education. ${ }^{30-33}$

Concept maps are useful for identifying and organizing concepts and their relationships to each other. A concept map is a two-dimensional, hierarchical node-link diagram that depicts the structure of knowledge within a scientific discipline as viewed by a student, an instructor, or an expert in a field. ${ }^{34}$ Cornwell has used concept maps for defining both course-level and curriculum-level content in mechanical engineering. ${ }^{35} \mathrm{He}$ finds that concept maps help students establish connections between the various topics and organize concepts in their minds. He suggests using concept maps as advance organizers, reference guides, and assessment tools. Harmon, et al. used concept maps (constructed knowledge maps) as both pretests and posttests to evaluate the extent to which students learned key concepts in a simulated design task in environmental engineering. ${ }^{36}$ In addition to course level assessment, Turns, et al. suggest using concept maps for assessment at the engineering program level to characterize level of expertise in a domain, identify discipline knowledge, and explore students' conceptions of engineering. ${ }^{37}$ While Streveler and Miller do not use the term 'concept map,' their work on the use of multidimensional scaling to identify student misconceptions gives insight into cognitive structures and the connections students make among series of concepts. ${ }^{38}$

Concept questions, also called concept tests, and coined as "ConcepTests" by Mazur, are used extensively in active learning and peer coaching environments, particularly in mathematics and science. According to Mazur, good concept questions focus on a single concept; are not solvable by relying solely on equations; reveal common difficulties with the concepts; and have several plausible answers based on typical student misunderstandings. ${ }^{39}$ In engineering, Danielson \& Mehta are developing banks of concept questions in the field of statics. They have tested the instructional effectiveness of the use of concept questions at two different institutions. ${ }^{40}$

\section{Concept Maps and Concept Questions in Aerospace Engineering at MIT}

In the sophomore multidisciplinary engineering course, we are developing concept maps to identify and organize key engineering concepts, and map the relationships of key ideas within and between disciplines. The disciplines covered in Unified Engineering include materials and structures, signals and systems, dynamics, thermodynamics, and fluids. The concept map of each discipline provides a means of communication between and among the faculty members team-teaching the course, and for the teaching assistants as well. The maps help faculty members plan class time more efficiently by sequencing concepts correctly, building upon the concepts taught by the other faculty members, and avoiding duplication and omission of important ideas. The maps also highlight areas where two or 
more disciplines link. The links are pointed out to students to help them understand how the disciplines are integrated, and are also used in the design of homework problems and in-class examples. (See Figure 1 to Figure 3 for sample concept maps.)

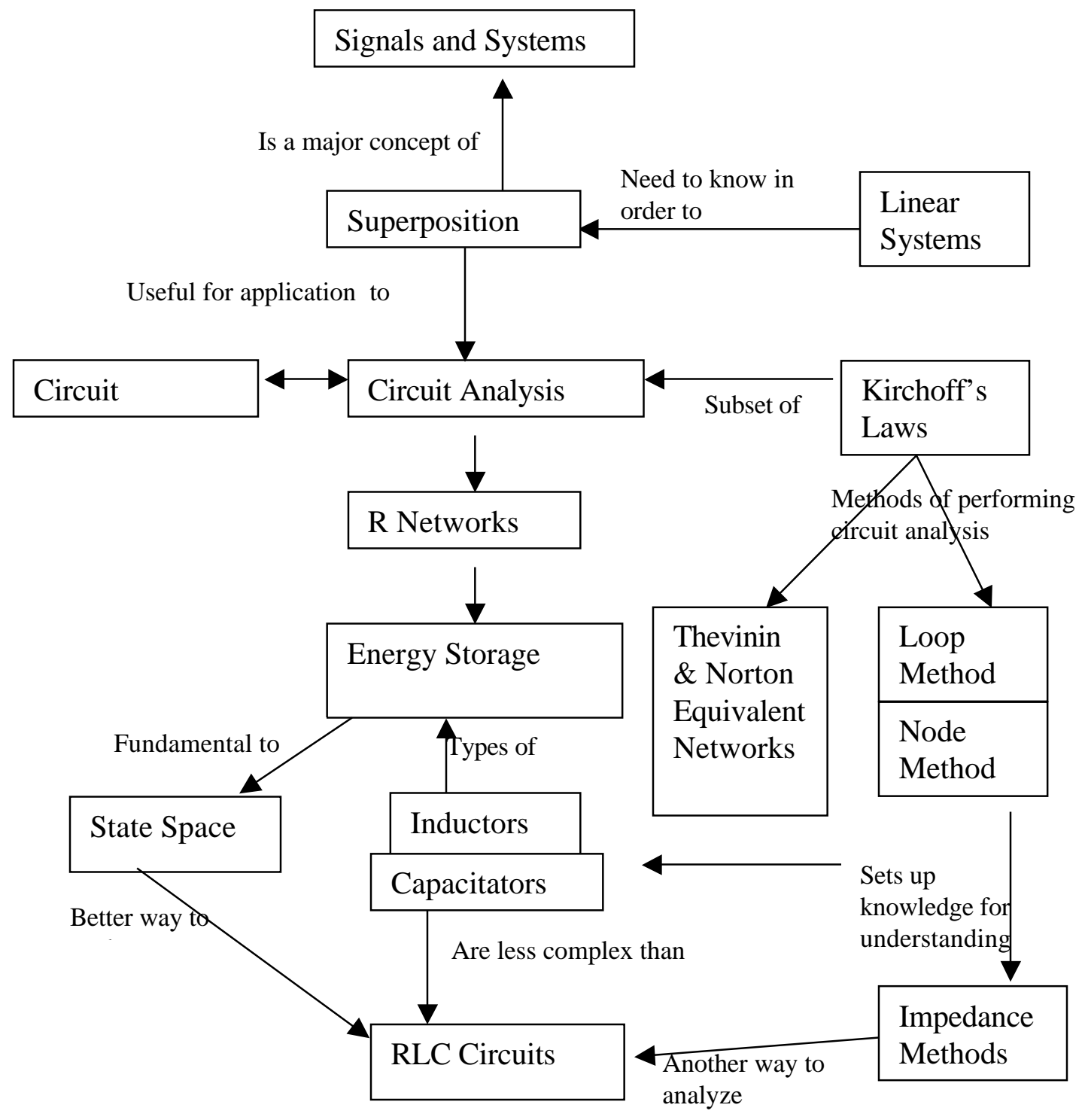

Figure 1: Early draft of a concept map for signals and systems 


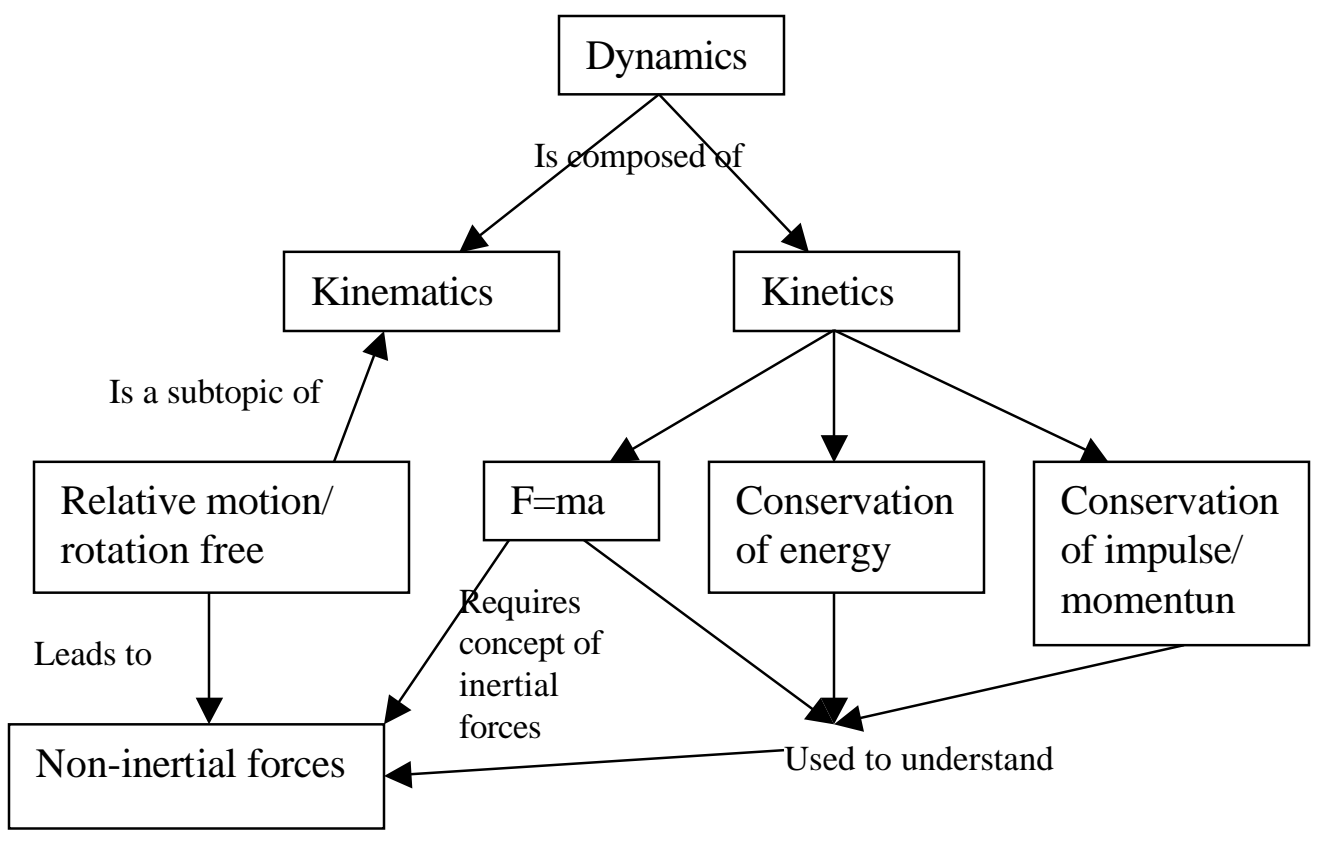

Figure 2: Early draft of a concept map for dynamics

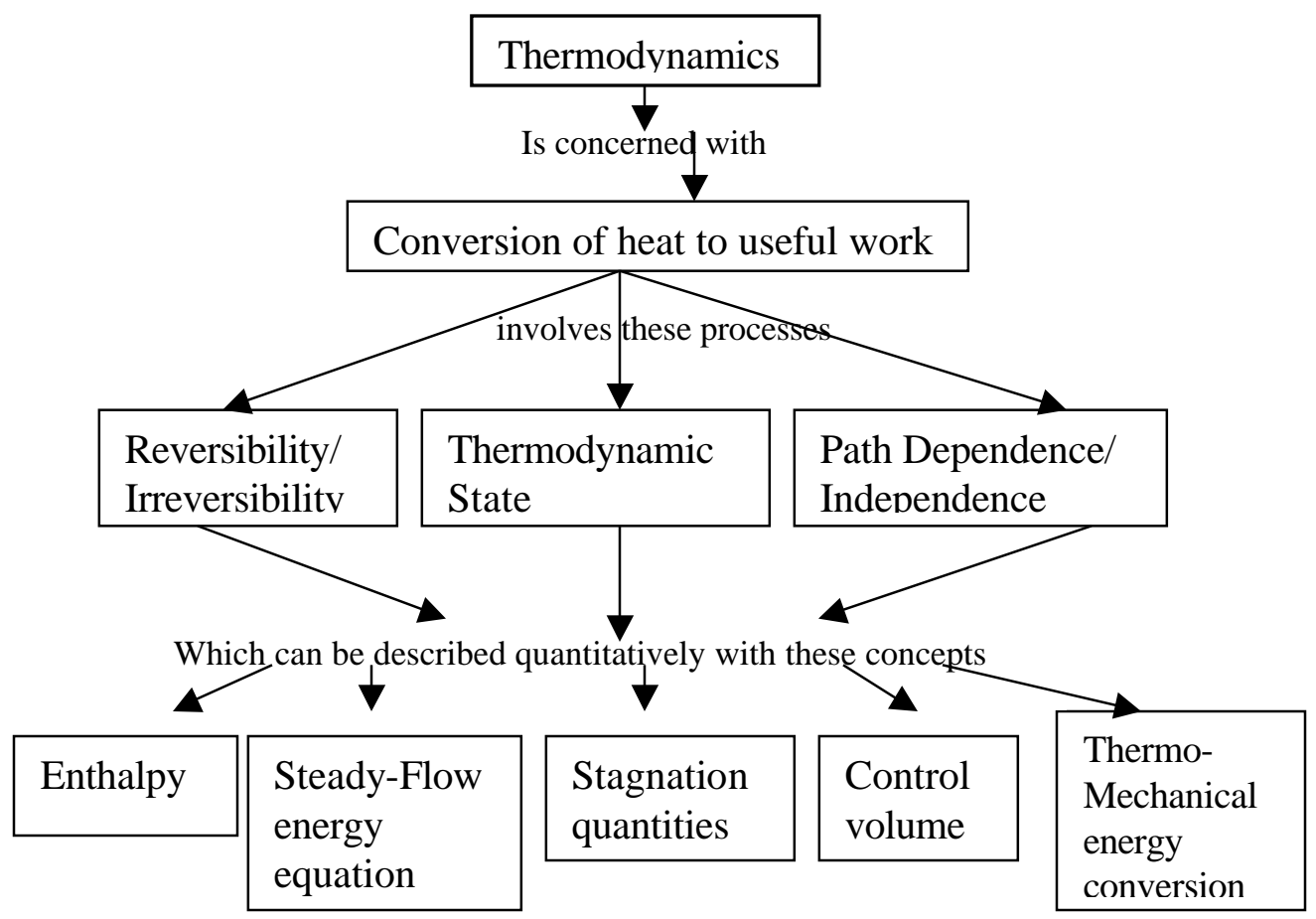

Figure 3: Early draft of a concept map for thermodynamics

Proceedings of the 2002 American Society for Engineering Education Annual Conference \& Exposition Copyright $\left({ }_{0}\right.$ 2002, American Society for Engineering Education 
In the future, we plan to ask students to create their own concept maps. Students can use their maps to check their own understanding of the concepts and plan their study time, as well as aid faculty in diagnosing and correcting student misconceptions.

In three MIT courses, Unified Engineering, Thermal Energy, and Aerodynamics, we use a peer instruction approach similar to that developed for physics by Mazur. ${ }^{41}$ In this approach, concept questions are given to students in class with time for individual thought and reflection. After a check to see how well students have understood the question, small group discussions are held (if needed) in which student groups attempt to answer the question. Afterward, the instructor clarifies misconceptions and leads students in further exploration of the concept. In the three courses discussed above, we measured class response through various techniques, including hand raising, flash cards, and, most recently, PRS, a personal response system. Interactive student response systems, such as PRS, have several advantages over hand raising or flash cards, e.g., anonymity of student responses and the generation of assessment data to analyze aggregate performance statistics. $^{42}$

Figure 4 to Figure 7 are samples of concept questions that we have used in our juniorlevel aerodynamics course. These questions address common misconceptions that found students possess entering the course or common misconceptions students have when first encountering new material. For example, the question in Figure 4 tests a misconception that a jet of water impinging on an object would tend to 'push' the object in the direction of the flow. This misconception is quite common as most people have had previous experience with the force and subsequent motion generated by a water stream impacting an object. However, the difference in this problem is that the water stream has a glancing contact which allows the stream to be turned as depicted in the figure. In actuality, the object will rotate clockwise, i.e., 'into the stream'; this can be easily demonstrated by application of conservation of momentum to the water stream and Newton's Law of equal and opposite forces. When we use this concept question, we include an in-class demonstration in which students can clearly observe the cylinder being drawn into the stream. Another advantage of this question is that it has a direct analogy with the manner in which lift is generated on an airfoil.

Our experience with the use of concept questions has shown that students' experience with the material prior to class is a critical aspect of success. In our aerodynamics course, reading assignments and homework are due prior to discussion of the material in class. The use of pre-class homework is a significant shift from traditional engineering pedagogy in which homework is assigned and due only after discussing the material in class. Not only is the pre-class homework critical to the success of active learning in the classroom, but it also encourages student self-learning. Furthermore, by scanning the homework assignments, student misconceptions and common difficulties can be detected immediately rather than weeks after discussing the material. Thus, in the spirit of active learning, preclass homework decreases feedback time between the students and teaching staff. Finally, we note that the shift from post-class to pre-class homework enables the homework to

Proceedings of the 2002 American Society for Engineering Education Annual Conference \& Exposition

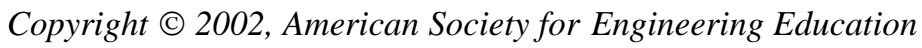


become a tool for formative, rather than summative, assessment. (See Figure 4 to Figure 7 for samples of concept questions.)

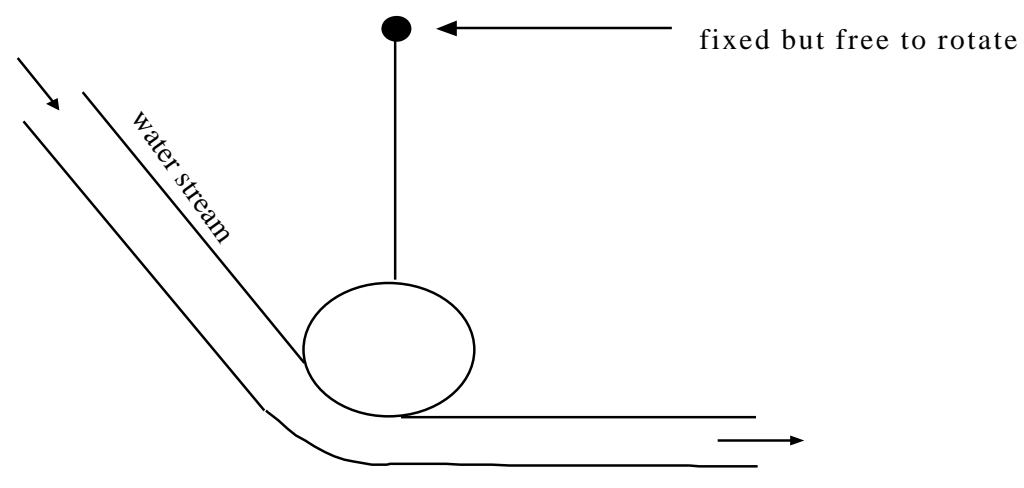

Given the water behaves as shown above, which direction will the cylinder rotate when the stream first makes contact with the cylinder?

(a) Clockwise

(b) Counter-clockwise

Figure 4: Flow turning and momentum change concept question

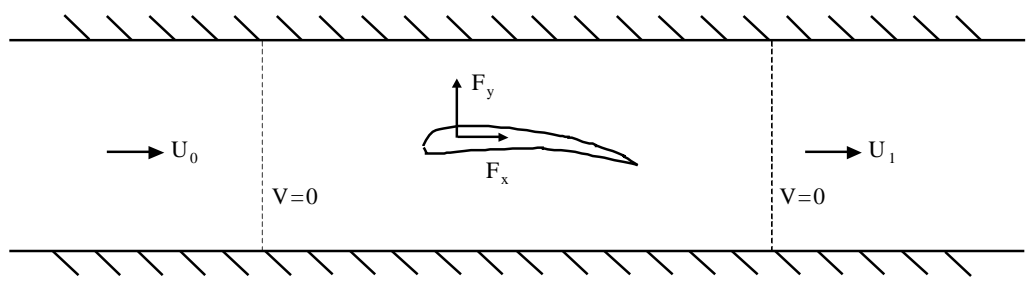

An airfoil which has $\mathrm{F}_{\mathrm{y}}>0$ when flying at speed $\mathrm{U}_{0}$ in the atmosphere is placed in a wind tunnel with a straight wall test section. The velocity a few chords upstrea $\mathrm{m} \&$ downstream is only in the $\mathrm{x}$ direction (i.e. $\mathrm{V}=0$ ). Which is most likely true?
(a) $\quad \mathrm{F}_{\mathrm{y}}>0$
(b) $\quad \mathrm{F}_{\mathrm{y}}<0$
(c) $\quad \mathrm{F}_{\mathrm{y}}=0$

Figure 5: Flow turning and force generation concept question 
Given the following streamlines for a steady, two dimensional fl ow:

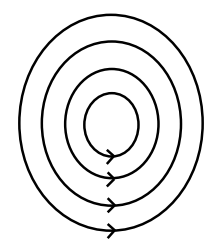

(a)

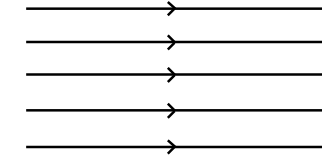

(b)

Which of these flows is irrotational:
(1) Only (a)
(2) Only (b)
(3) Both (a) \& (b)
(4) Neither

Figure 6: Irrotationality and streamline concept question

An airfoil has the following $C_{d}$ vs. $R e$

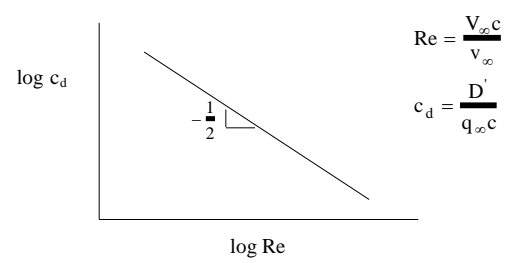

At $\mathrm{V}_{\infty}=\mathrm{V}_{1}$, the drag on the airfoil is $\mathrm{D}_{1}^{\prime}$.

For $\mathrm{V}_{\infty}=2 \mathrm{~V}_{1}$, the drag on the airfoil is $\mathrm{D}_{2}$.
(a) $\mathrm{D}_{1}^{\prime}>\mathrm{D}_{2}^{\prime}$
(b) $\mathrm{D}_{1}^{\prime}=\mathrm{D}_{2}^{\prime}$
(c) $\mathrm{D}_{1}^{\prime}<\mathrm{D}_{2}^{\prime}$
(d) Not enough info

Figure 7: Drag and drag coefficient concept question 


\section{Processes for Developing Concept Maps and Concept Questions}

During our initial attempts to engage students more actively in their own conceptual learning, we employed a variety of approaches for developing concept maps and concept questions, including

Instructor knowledge: Instructor knowledge is a valuable resource for identifying difficult concepts and writing questions that illustrate and assess these concepts. Instructors understand from past teaching experiences what are the most common difficulties in their subjects. In informal interviews conducted by colleagues and education specialists, instructors identify difficult concepts in their disciplines, based on the learning objectives and outcomes of their courses. The purpose of the interviews is to develop lists of concepts that are required to achieve the measurable outcomes, to select those concepts that are most difficult for students to master, and to document the known misconceptions which lead to learning difficulties.

Instructional staff collaboration: In the large sophomore multidisciplinary core course, a team of faculty, undergraduate and graduate teaching assistants comprise the instructional staff. The creation of concept maps was a collaborative effort. To develop concept maps for each of the disciplines, key concepts were identified from course syllabi and written on Post-it notes ${ }^{\circledR}$. The faculty member in charge of the discipline checked the concepts and added or deleted as necessary. A brief explanation about constructing concept maps was given at the weekly course staff meeting. Following that, groups of faculty and teaching assistants worked together to arrange and re-arrange the Post-it Notes ${ }^{\circledR}$ into a map. Completion of the maps took place over several weeks during the course staff meetings. Faculty members then refined the maps in individual sessions with the department instructional designer. Sharing the completed maps at a course staff meeting was an important step for course planning, teaching and learning activities, homework problems, and identifying areas of possible student misconception or confusion.

Muddiest-point-in -the-lecture/reading/homework: In the aerospace engineering curriculum at MIT, we use student feedback to identify the part of the lecture, reading, and/or homework that is most confusing or difficult. During the next few years, the "muddy card" data will be continually collected, analyzed, and compared with the lists of key concepts and associated misconceptions.

Open-ended concept questions: Once an initial set of concepts is selected, students are asked to respond to open-ended concept questions, either in-class or as part of a written homework assignment. Student responses frequently contain a few consistent misconceptions that can then be used as the focus of new concept questions.

Student-developed concept questions: Taking the open-ended concept question technique a step farther, we ask students to generate concept questions as part of a pre-class homework assignment on new concepts. Students are given a description of a good concept question, shown a few examples, and asked to develop new concept questions based on the assigned reading. Students must also provide a solution (or set of reasonable 
solutions) to each question. Many of the students' concept questions can be used with only minor changes. More often, the student identifies a difficult concept and, through his/her answers to the concept question, demonstrates some of the underlying reasons for the conceptual difficulty. Often, the answer that the student believes is the "correct" answer to the concept question is, in fact, somewhat or completely incorrect. This occurrence can also be very useful in writing concept questions

\section{Current Plans}

We are currently focusing on the development of a comprehensive set of concepts in aerodynamics and thermodynamics and related aerospace disciplines. We plan to develop and refine corresponding concept maps and concept questions. In another year, we anticipate having a fairly comprehensive database of concept questions. The database will be continually refined and extended and the use of the open-ended and student-developed concept question strategies will also be explored.

With the extended use of concept maps and concept questions in the classroom, more systematic assessment of student conceptual understanding will be implemented. While we have data on student perceptions of their understanding and their satisfaction with their learning experiences, we have little evidence documenting students' growth in conceptual understanding as a result of using concept maps and concept questions. Our initial efforts with oral examinations of aerodynamics concepts are leading in promising directions.

\section{Summary}

The Department of Aeronautics and Astronautics at MIT is making progress in its methods to enhance conceptual understanding with the use of concept maps and concept questions. At the present time, concept maps and concept questions have been developed in basic thermodynamics, structures, signals and systems, dynamics, controls, advanced aerodynamics and thermal energy, and are being used by several undergraduate instructors in their courses. We have collected data on their use, and have initiated plans for a concept questions database. Our next steps are to implement a more systematic approach to assessment of the effectiveness of concept maps and concept questions in the improvement of students' conceptual understanding.

\section{Acknowledgements}

The authors gratefully acknowledge the Unified Engineering instructional staff for their efforts and contributionsto the concept maps.

\section{Bibliography}

1. Smith, P. L., and T. J. Ragan, Instructional Design, 2d ed., Merrill, Upper Saddle River, NJ, 1999.

2. Wiggins, G., and J. McTighe, Understanding By Design, Association for Supervision and Curriculum Development, Alexandria, VA, 1998.

Proceedings of the 2002 American Society for Engineering Education Annual Conference \& Exposition Copyright $\left({ }^{\circ}\right.$ 2002, American Society for Engineering Education 
3. Mintzes, J. J., J. H. Wandersee, and J. D. Novak (Eds.), Teaching Science for Understanding: A Human Constructivist View, Academic Press, New York, 1998.

4. Zeilik, M., Concept Mapping, 2000. Available at http://www.wcer.wisc.edu/nise/cl1/flag

5. Ellis, A. B., C. R. Landis, and K. Meeker, ConcepTest, 2000. Available at http://www.wcer.wisc.edu/nise/cl1/flag

6. Mazur, E., Peer Instruction: A User's Manual, Prentice-Hall, Upper Saddle River, NJ, 1997.

7. Angelo, T. A., and K. P. Cross, Classroom Assessment Techniques: A Handbook for College Teachers, $2^{\text {nd }}$ ed., Jossey-Bass, San Francisco, 1993.

8. Mosteller, F., "The 'Muddiest Point in the Lecture', as a Feedback Device," In Teaching and Learning:The Journal of the Harvard-Danforth Center, Vol. 3, 1989.

9. Reference 6.

10. Personal Response System, $P R S$, http://www.educue.com

11. Felder, R. M., and R. Brent, "Navigating the Bumpy Road to Student-Centered Instruction", College Teaching, 1996, pp. 43-47.

12. Hake, R. R., "Interactive-Engagement vs. Traditional Methods: A Six-Thousand-Student Survey of Mechanics Test Data for Introductory Physics Courses", American Journal of Physics, v. 66 no. 1, 1998, pp. 64-74.

13. Heller, P., and M. Hollobaugh, "Teaching Problem Solving Through Cooperative Grouping, Part 2: Designing Problems and Structuring Groups", American Journal of Physics, v. 60 no. 7, 1992, pp. 637-644.

14. Heller, R., R. Keith, and S. Anderson, " Teaching Problem Solving Through Cooperative Grouping, Part 1: Group vs. Individual Problem Solving", American Journal of Physics, v. 60 no. 7, 1992, pp. 627-636.

15. Johnson, D. W., and R. T. Johnson, Cooperation and competition: Theory and Research, Interaction Book Company, Edina, MN, 1989.

16. Johnson, D. W., and R. T. Johnson, Meaningful and Manageable Assessment Through Cooperative Learning, Interaction Book Company, Edina, MN, 1996.

17. Johnson, D. W., R. T. Johnson, and K.A. Smith, Active Learning: Cooperation in the College Classroom, Interaction Book Company, Edina, MN, 1991.

18. Meltzer, D. E., and K. Manivannan, "Promoting Interactivity in Physics Lecture Classes", Physics Teacher, v. 34, 1996, pp. 72-76.

19. Gagne, R. M., The Conditions of Learning, 3rd ed., Holt, Rhinehart, and Winston, New York, 1977.

20. Reference 2 .

21. National Research Council, How People Learn: Brain, Mind, Experience, and School, National Academy Press, Washington, DC, 2000. Available at http://books.nap.edu/books/0309070368/html/index.html.

22. Reference 1.

23. Reference 20.

24. Posner, G., K. Strike, P. Hewson, and W. Gerzog, "Accommodation of a Scientific Conception: Toward a Theory of Conceptual Change", Science Education, v. 66, 1982, pp. 211-227

25. Reference 6.

26. Reference 3.

27. Novak, J. D., Learning, Creating, and Using Knowledge: Concept Maps as Faci litative Tools in Schools and Corporations, Lawrence Erlbaum Associates, New York, 1998.

28. Plotnik, E., Concept Mapping: A Graphical System for Understanding the Relationship Between Concepts, 1997. (ERIC Document Reproductions Service No. ED407938). Available at http://ericir.syr.edu/plweb-cgi/obtain.pl

29. Novak, J. D. and D.B. Gowin, Learning How to Learn, Cambridge University Press, Cambridge, UK, 1984.

30. Cornwell, P. J., "Concept Maps in the Mechanical Engineering Curriculum", Proceedings of the 2000 American Society of Engineering Education Annual Conference and Exposition, 2000. Available at http://www.asee.org/conferencessearch.

Proceedings of the 2002 American Society for Engineering Education Annual Conference \& Exposition Copyright $\left({ }^{\circ}\right.$ 2002, American Society for Engineering Education 
31. Danielson, S., and S. Mehta, "Statics Concept Questions for Enhancing Learning", Proceedings of the 2000 American Society of Engineering Education Annual Conference and Exposition, 2000. Available at http://www.asee.org/conferencessearch.

32. Harmon, T. C., G. A. Burks, G. Chung, and E. Baker, "Evaluation of a Simulation and Problem Based Learning Design Project Using Constructed Knowledge Mapping", Proceedings of the 2001 American Society of Engineering Education Annual Conference and Exposition, 2001. Available at http://www.asee.org/conferencessearch.

33. Turns, J., C.J. Atman, and R, Adams, "Concept Maps for Engineering Education: A Cog nitively Motivated Tool Supporting Varied Assessment Functions", IEEE Transactions on Education, v. 43, no. 2, 2000, pp. 164-173.

34. Reference 4.

35. Reference 30.

36. Reference 32.

37. Reference 33.

38. Streveler, R. A., and R. L. Miller, "Investigating Student Misconceptions in the Design Process Using Multidimensional Scaling", Proceedings of the 2001 American Society of Engineering Education Annual Conference and Exposition, 2001. Available at http://www.asee.org/conferencessearch.

39. Reference 6.

40. Reference 31 .

41. Reference 6.

42. Reference 10.

\section{DAVID L. DARMOFAL}

David L. Darmofal is an Associate Professor in the Department of Aeronautics and Astronautics at M.I.T., where he teaches courses in aerodynamics and numerical methods. His research interests focus on the development of next-generation computational tools for aerospace applications. In 1996, he received an NSF CAREER award.

\section{DIANE H. SODERHOLM}

Diane Hauer Soderholm is the Instructional Designer in the Department of Aeronautics and Astronautics at MIT. She collaborates with faculty to investigate, pilot and implement new teaching approaches, designs and revises courses and curriculum, and participates in the many educational initiatives in which the department is currently engaged.

\section{DORIS R. BRODEUR}

Doris R. Brodeur is the Director of Learning Assessment in the Department of Aeronautics and Astronautics at MIT. She is responsible for designing and implementing assessment of the department's educational initiatives. She has been conducting assessment and evaluation acti vities for more than twenty years in K-12 schools, higher education, corporate education, and international projects. 